\title{
The Prevalence and Patient Characteristics of Primary Antibody Deficiencies in a Tertiary Care Setting in North Cyprus
}

\author{
Özel Yürüker' (1), Burçin Șanlıdağ2 ${ }^{(D)}$, Nerin Nadir Bahçeciler² (1) \\ 'Department of Immunology, University of Kyrenia School of Medicine, Kyrenia, Cyprus \\ ${ }^{2}$ Department of Pediatrics, Near East University School of Medicine, Nicosia, Cyprus
}

ORCID IDs of the authors: O.Y. 0000-0002-9770-076I; B.S. 0000-0003-I0II-475X; N.B. 0000-0003-I337-204I.

Cite this article as: Yürüker O, Șanlıdağ B, Bahçeciler NN. The Prevalence and Patient Characteristics of Primary Antibody Deficiencies in a Tertiary Care Setting in North Cyprus. Cyprus J Med Sci 2020; 5(I): I-6.

\section{BACKGROUND/AIMS}

Primary antibody deficiencies (PADs) are the most common group of primary immunodeficiency disorders that present with a wide range of clinical features. We conducted this study to evaluate the frequency and characteristics of patients with PADs.

\section{MATERIAL and METHODS}

The medical records of 160 children (M:F 99:6I, mean age 42.39 28.44 months) were retrospectively reviewed from the Near East University Hospital database. Children who had PADs were then compared according to their demographic, clinical, and laboratory findings.

\section{RESULTS}

A total of 97 children were diagnosed with PADs (49 THGI, 3I IgGD, I SIgAD, 8 CVID, 6 IgMD, and 2 PHGI)*. Patients with THGI had the youngest age at the time of diagnosis (27 \pm 16.40 months), and those with CVID had the oldest age at the time of diagnosis ( $81.62 \pm 49.9$ months old) compared with children in other PAD groups. In the HGG group, 63.9\% of children presented with both recurrent wheezing/ cough and infections, $22.7 \%$ had only recurrent infection, $13.4 \%$ of them had only recurrent wheezing/cough, and $71.7 \%$ of the children were atopic. At the end of the 2-year follow-up period, 8 patients (5 THGl and $3 \mathrm{lgGSD}$ ) out of 70 with HGG recovered.

\section{CONCLUSION}

PADs generally present with recurrent infections and/or recurrent bronchoconstriction unresponsive to standard asthma treatment. Evaluation of the immune system is important to increase the quality of life of these patients and also decrease the healthcare costs.

Keywords: Allergy, hypogammaglobulinemia, immunoglobulin, recurrent infections

\section{INTRODUCTION}

Primary immunodeficiency disorders (PID) are defined on the basis of the component of the body's immune system that is missing or not functioning properly (I). These disorders are caused due to hereditary genetic defects. Approximately 300 single gene disorders have been reported with underlying symptoms, including recurrent infections, allergy, autoimmunity, and malignancy (2). Hypogammaglobulinemia (HGG) is one of the major groups of PIDs that is caused due to various defects in the B-cell lineage or B-cell function resulting in low levels of immunoglobulins in the blood circulation. This affects the body's immune response and causes a broad spectrum of clinical features ranging from asymptomatic diseases to severe and recurrent infections, chronic inflammation, and autoimmunity (3). Major B-cell immunodeficiencies include transient hypogammaglobulinemia of infancy (THGI), IgM deficiency (IgMD), Bruton agammaglobulinemia, selective IgA deficiency (SIgAD), IgG subclass deficiency (IgGSD), and common variable immunodeficiency (CVID) (4).

The majority of patients can lead normal lives by taking prophylactic antibiotics. However, those with severe infections require intravenous immune serum globulin (IVIG) treatments (5).

*Abbreviations: CVID, common variable immune deficiency; THGI, transient hypogammaglobulinemia of Infancy; PHGI, protracted hypogammaglobulinemia of infancy; IgMD, IgM deficiency; SlgAD, selective IgA deficiency; IgGSD, IgG subclass deficiency. 
Epidemiological studies have reported geographical and racial variations in both the prevalence and pattern of immunodeficiencies (6). In adults, IgA deficiency is the most common disorder (I:400-800). Bruton (X-linked) agammaglobulinemia affects I in 10,000-200,000 males, whereas females do not manifest any clinical symptoms as they are only carriers (7). The incidence rate of CVID is 1:10,000-50,000 depending on particular race (I).

The national registry for incidence and prevalence rates of PID diseases is currently not available in North Cyprus. Early diagnosis of hypogammaglobulinemia is important to prevent fatal results and complications during the follow-up period of their current symptoms.

In the present study, we aimed at determining the rate of any humoral PID diseases among children who were admitted to our hospital, which is a tertiary care setting in North Cyprus.

\section{MATERIAL AND METHODS}

\section{Ethical Approval}

This study was approved by the Institutional Ethics Evaluation Board (2017/43-359) on January 18, 2017.

\section{Informed Consent}

Informed consent was not necessary as this was a retrospective study.

\section{Study Population}

This investigation was designed as a single-center retrospective study including those children who were under follow-up in the Division of Paediatric Allergy and Immunology in the tertiary hospital in Cyprus for a 3-year interval.

Children who had recurrent infection (8-10) and/or recurrent wheezing/cough and were unresponsive to standard asthma medications (II) were investigated for HGG.

Children who did not apply to the Division of Paediatric Allergy and Immunology and/or had secondary immunodeficiencies, e.g., HIV, were excluded based on a commercially available ELISA test combo reagent kit for detecting HIV Ag/Ab (Architect System, Abbott, Wiesbaden, Germany).

\section{Study Design}

The demographic, clinical, and laboratory data of the children included in this study were collected from the hospital's database retrospectively.

\section{Main Points:}

- The admission to the hospital of PAD patients were mainly, recurrent infections and/or recurrent bronchiolitis unresponsive to standard asthma treatment.

- $\quad$ THGl had been found to be the major subgroup of PAD in which $10 \%$ of them recovered in a 2 year follow up period.

- Early diagnosis and the follow up period of PAD are important in order to increase the quality of life of the patients as well as to decrease the healthcare costs.
Details regarding gender, age, family history of immunodeficiency, allergy, recurrent infections, follow-up period, remission of hypogammaglobulinemia, initial and final treatments, serum Ig levels, IgG subgroup levels, lymphocyte subset percentages, specific antibody responses, skin prick test, or allergen-specific IgE results were recorded.

\section{Follow-up Period and Treatment}

Patients who had fewer than six mild infections in a year were not given prophylactic treatment.

Patients who had more than six infections such as upper respiratory tract infections, otitis media, sinusitis, and gastroenteritis requiring antibiotic treatment were administered an oral prophylactic treatment with trimethoprim-sulfamethoxazole (Trim-Sulf).

Those who failed to respond to the oral antibiotic prophylaxis and those who required hospitalization two or more times a year due to severe infections such as pneumonia, bronchopneumonia, and cellulitis were administered IVIG at a dosage of 0.5 $\mathrm{g} / \mathrm{kg}$ every $2 \mathrm{l}$ days.

For the treatment of asthma, inhaled corticosteroids (ICSs) were used as a first-line medication. The dosage of ICSs was adjusted according to the severity of symptoms based on GINA guideline recommendations (II). The patients were examined every 2 months to adjust the ICS dosage.

The immune system was evaluated by measuring the serum Ig and lgG subclass levels. Further tests such as determination of the lymphocyte subset percentages and the specific antibody responses were performed if indicated by the clinician.

\section{Laboratory Studies}

\section{Atopy}

For the determination of the presence of atopy, skin prick tests were performed using $2 \mathrm{l}$ common aeroallergens, including Dermatophagoides farinae, D. pteronyssinus, Alternaria, AspergilIus mix, Penicillium mix, Candida albicans, Betulaceae, Aesculus hippocastanum, Olea europaea, Plantago, Artemisia, Parietaria, Secale cereale, Triticum vulgaris, Acacia dealbata, and a mixture of five grasses, feathers, cat hair, dog hair, and cockroach (Stallergenes, Antony, France). Histamine and saline were used as positive and negative controls, respectively. A drop of each allergen extract was placed on the volar surface of the left forearm and penetrated using a staller point. After $15 \mathrm{~min}$, the wheal reaction was measured as the mean of the longest diameter and the diameter perpendicular to it. A wheal diameter of at least $3 \mathrm{~mm}$ greater than that in the negative control was considered as positive.

\section{Immunological Tests}

All the equipment used for laboratory analyses are calibrated routinely in the laboratory of our hospital. Furthermore, negative and positive control samples were used before analyzing the patient's serum samples.

\section{Assessment of Immunoglobulin Levels}

Peripheral venous blood samples of the patients were centrifuged at 2000 $\mathrm{g}$ for 10 min to obtain serum. 
Serum Ig $G$, IgA, and IgM levels were measured by the turbidimetric method using Roche Cobas c3ll and commercially available kits (Roche Diagnostics, Mannheim, Germany).

Serum IgE levels were measured by fully automated ELISA, Roche Cobas e4II using commercially available kits (Roche Diagnostics, Mannheim, Germany).

Serum Ig $G$ subclasses ( $\lg G 1, \lg G 2$, and $\lg G 3$ ) were evaluated by nephelometry using commercially available kits.

All Ig results were evaluated according to the normal $\pm 2 S D$ values based on the levels of healthy Turkish children according to age (12). Values lower than 2SD were accepted as low.

\section{Lymphocyte Subset Analysis}

Lymphocyte subpopulation analysis was performed by flow cytometry (BD FACS Calibur, BD Biosciences, San Jose, CA, USA). Lymphocyte subsets derived from peripheral blood were counted by fluorescence-activated cell sorting (FACS), including total lymphocytes (CD45+), total T cells (CD3), helper T cells (CD3+ / CD4+), cytotoxic T cells (CD3+/CD8+), B cells (CDI9+), NK cells (CDI6/56+), and active T cells (CD3/anti-HLA DR). The results were evaluated according to the normal $\pm 2 S D$ values based on the age of Turkish children (13). Values lower than 2SD were accepted as low.

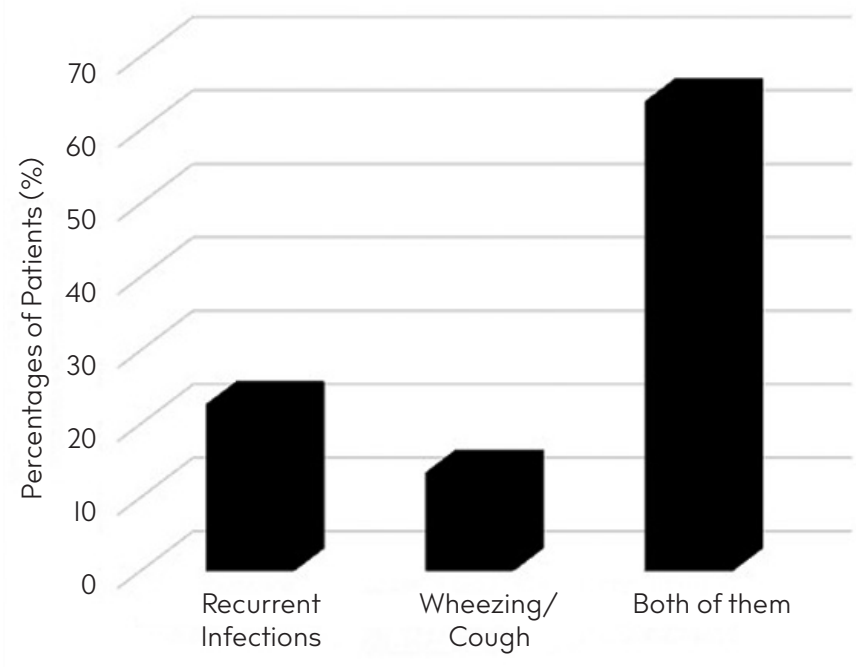

Reason of Admission

FIGURE I. Number of patients with HGG according to the reason of admission

HGG: hypogammaglobulinemia

\section{Antigen-specific Antibody Response}

Antigen-specific antibody responses were evaluated by anti-tetanus toxoid Ig G antibody levelEurolmmune lgG ELISA (catalog no: El 2060-960l G) Pneumococcus IgG, ELiZEN/ ZenTech (catalog no: E-DG-96), and anti-Hbs, fully automated ELISA Roche Cobas e4II (catalog no: El 2060-960I G) using commercially available kits (Roche Diagnostics, Mannheim, Germany).

\section{Statistical Analysis}

Statistical analyses were performed using the IBM SPSS software package for Windows (release 20.0.0, SPSS Inc., Chicago, III, USA). In the descriptive statistics, prevalence rates were expressed as mean (SD) and percentages. Chi-square, KruskalWallis, and Mann-Whitney $U$ tests were used for analyses. $P$ values $<0.05$ were considered to be statistically significant.

\section{RESULTS}

A total of 160 children, including 61 (38.1\%) females and 99 (61.9\%) males, who met the inclusion criteria were enrolled in this study. Of these children, 35 (21.9\%) were admitted with recurrent infections, 25 (16.6\%) had with recurrent cough/wheezing, and $100(62.5 \%)$ children had both recurrent infections and recurrent cough/wheezing. After further laboratory investigations, 97 (60.6\%) children were diagnosed with humoral PID and defined as the hypogammaglobulinemia (HGG) group (mean $\pm S D$ age: $43.07 \pm 30.67$ months, male/female: 66/31). The number, gender, and mean age of these patients were presented according to the type of PID that they had at the time of diagnosis The most frequently diagnosed immune deficiency diseases among the children with HGG were THGI 49 (50.5\%) and lgG subclass deficiency 31 ( $32 \%)$. The mean age at the time of diagnosis was 27 months for patients with THGI, 57.35 months for those with IgGSD, 49 months for those with SlgAD, 81.62 months for children with CVID, 40.50 months for those with IgMD, and 66 months for children with protracted hypogammaglobulinemia (PHGI) (Table I).

In the HGG group, the majority of children (63.9\%) had both recurrent wheezing/cough and infections, $22.7 \%$ of them had only recurrent infection, and $13.4 \%$ of the children presented with only recurrent wheezing/cough that was unresponsive to standard asthma treatment (Figure I).

Among the 49 children who were diagnosed with THGI, 29 were admitted to the hospital with both recurrent cough/wheezing and recurrent infections, of whom 14 had only recurrent infections and 6 had recurrent wheezing/cough.

Among the majority of children who were diagnosed with IgG subgroup deficiency, 20 (64.5\%) had recurrent infection togeth-

TABLE I. Patients' demographic data according to their PADs

THGI

$\lg G S D$

$\operatorname{Slg} A D$

CVID

$\lg M D$

PHGI

Number

$n(\%)$

Gender (Male/Female)

$49(50.5)$

31 (32)

I (I)

8 (8.2)

$6(7.9)$

$2(2.1)$

Age at the time of Diagnosis (months $\pm S D$ )

$37 / 12$

$16 / 15$

$1 / 0$

$5 / 3$

$5 / 1$

$2 / 0$

$27.00 \pm 16.40$

$57.35 \pm 29.05$

$49.00 \pm 0.00$

$81.62 \pm 49.96$

$40.50 \pm 18.45$

$66.00 \pm 7.07$

PAD: primary antibody deficiency; CVID: common variable immune deficiency; THGI: transient hypogammaglobulinemia of Infancy; PHGI: protracted hypogammaglobulinemia of infancy; IgMD: IgM deficiency; SIgAD: selective IgA deficiency; IgGSD: IgG subclass deficiency. 
er with wheezing/cough, 6 (19.3\%) had only recurrent infection, and 5 had only wheezing/cough.

Patients who were admitted to the Division with complaints of only asthmatic symptoms belonged to the THGI, Ig subgroup deficiency, PHGI and IgM deficiency groups, 6 (I2.2\%), 5 (I6.1\%), I (I00\%), and I (I00\%) in numbers respectively (Table 2 ).

TABLE 2. Reasons of admission among patients with PAD

\begin{tabular}{|c|c|c|c|}
\hline \multirow[b]{2}{*}{ PADs $(n=97)$} & \multicolumn{3}{|c|}{ Diagnosis at admission $\mathrm{n}(\%)$} \\
\hline & $\begin{array}{l}\text { Recurrent } \\
\text { Infection }\end{array}$ & $\begin{array}{l}\text { Recurrent } \\
\text { wheezing/ } \\
\text { cough }\end{array}$ & $\begin{array}{c}\text { Both of } \\
\text { them }\end{array}$ \\
\hline THGI $(n=49)$ & $14(28.6 \%)$ & $6(12.2 \%)$ & $29(59.1 \%)$ \\
\hline $\lg G S D(n=3 \mid)$ & $6(19.4 \%)$ & $5(16.1 \%)$ & $20(64.5 \%)$ \\
\hline $\operatorname{Slg} A D(n=1)$ & $0(0.0 \%)$ & $0(0.0 \%)$ & I (I00\%) \\
\hline$C \vee I D(n=8)$ & I (I00\%) & $0(0.0 \%)$ & $7(87.5 \%)$ \\
\hline $\lg M D(n=6)$ & $0(0.0 \%)$ & I (100\%) & $5(83.3 \%)$ \\
\hline PHGI $(n=2)$ & I (100\%) & $\mathrm{I}(100 \%)$ & $0(0.0 \%)$ \\
\hline \multicolumn{4}{|c|}{$\begin{array}{l}\text { PAD: primary antibody deficiency; CVID: common variable immune } \\
\text { deficiency; THGI: transient hypogammaglobulinemia of Infancy; PHGI: } \\
\text { protracted hypogammaglobulinemia of infancy; IgMD: IgM deficiency; } \\
\text { SIgAD: selective IgA deficiency; IgGSD: IgG subclass deficiency. }\end{array}$} \\
\hline
\end{tabular}

TABLE 3. Family history of allergic diseases, PADs, and consanguineous marriage for patients with PAD

\begin{tabular}{|lccc|} 
& \multicolumn{3}{c}{ Family History } \\
\cline { 2 - 4 } & $\begin{array}{c}\text { Allergic } \\
\text { Diseases }\end{array}$ & PAD & $\begin{array}{c}\text { Consanguineous } \\
\text { Marriage }\end{array}$ \\
\hline PADs $(n=97)$ & \multicolumn{3}{c}{ No of cases (\%) } \\
\hline $\operatorname{THGI}(n=48)$ & $18(37.5)$ & I (2.0) & $2(4.2)$ \\
$\operatorname{lgGSD}(n=30)$ & $19(63.3)$ & $2(6.7)$ & $0(0.0)$ \\
$\operatorname{SIgAD}(n=1)$ & $0(0.0)$ & $0(0.0)$ & $0(0.0)$ \\
$\operatorname{CVID}(n=7)$ & $4(57.14)$ & $1(14.3)$ & $0(0)$ \\
$\operatorname{lgMD}(n=6)$ & $3(50)$ & $2(33.3)$ & $I(16.7)$ \\
$\operatorname{PHGI}(n=1)$ & $0(0.0)$ & $0(0.0)$ & $0(0.0)$ \\
\hline
\end{tabular}

PAD: primary antibody deficiency; CVID: common variable immune deficiency; THGI: transient hypogammaglobulinemia of Infancy; PHGI: protracted hypogammaglobulinemia of infancy; IgMD: IgM deficiency; SIgAD: selective IgA deficiency; IgGSD: IgG subclass deficiency.

TABLE 4. Medications that were given to patients with PAD

\begin{tabular}{|c|c|c|c|c|}
\hline $\begin{array}{l}\text { Diagnosis } \\
\text { (n) }\end{array}$ & $\begin{array}{c}\text { Trim-sulf } \\
\mathrm{n}(\%)\end{array}$ & $\begin{array}{l}\text { IVIG } \\
\text { n (\%) }\end{array}$ & $\begin{array}{l}\text { Trim-sulf + } \\
\text { IVIG } \\
\text { n(\%) }\end{array}$ & $\begin{array}{l}\text { No. of patients } \\
\text { requiring } \\
\text { treatment } n(\%)\end{array}$ \\
\hline THGI $(n=49)$ & $16(32.7)$ & I (2) & - & $17(17)$ \\
\hline CVID $(n=8)$ & $6(75)$ & I (12.5) & - & $7(87.5)$ \\
\hline $\operatorname{lgGSD}(n=3 \mid)$ & $9(29)$ & - & - & $9(29)$ \\
\hline $\lg M D(n=6)$ & - & - & I (16.7) & I (16.7) \\
\hline
\end{tabular}

PAD: primary antibody deficiency; CVID: common variable immune deficiency; THGI: transient hypogammaglobulinemia of Infancy; PHGI: protracted hypogammaglobulinemia of infancy; IgMD: IgM deficiency; SIgAD: selective IgA deficiency; IgGSD: IgG subclass deficiency; TrimSulf: Trimethoprim/sulfamethoxazole; IVIG: Intravenous immunoglobulin.
Among the HGG group, $71.7 \%$ of patients were sensitive to at least one allergen. Atopy was present in 53.1\% of children in the non-HGG group (Figure 2).

The highest rate of atopy was observed in patients with Ig subgroup deficiency [17/23 (73.9\%)], followed by patients with THGI $[17 / 25(68 \%)]$.

Among the group with primary antibody deficiencies (PADs; 97 patients), 60 patients were evaluated for atopy, and it was detected in 43/60 (71.7\%) children with PADs. Among these patients, 17/25 (68\%) had THGI, 17/23 (73.9\%) had lgGSD, 5 (83.3\%) had CVID, and $2(50 \%)$ had IgMD.

Children in the HGG group were further evaluated based on the family history of allergic diseases, PADs, and consanguineous marriage of parents, whose prevalence rates were found to be $48.4 \%, 6.4 \%$, and $3.2 \%$, respectively.

Children who were diagnosed with IgMD had the highest prevalence of positive family history for both allergic diseases (50\%) and PADs (33.3\%) and also for the presence of consanguineous marriage among their parents (16.7\%) (Table 3).

\section{Treatment Follow-up}

Patients with HGG were followed up for 2-48 months, with a mean follow-up period of 13 months.

Among patients with HGG, 3 (3.1\%) were under IVIG treatment, 31 (32\%) were under Trim-Sulf prophylaxis, and 25 (26.9\%) were followed up without any medication.

Medications that were administered to the patients are summarized in (Table 4).

A total of 70 patients who had hypogammaglobulinemia were followed up for 2 years. During this period, eight patients had recovered, including five in the THGI group and three in the lgG3 subgroup deficiency group, indicating recovery rates of 4/40 $(12.5 \%)$ and $3 / 17(17.6 \%)$, respectively, during the 2 -year follow-up.

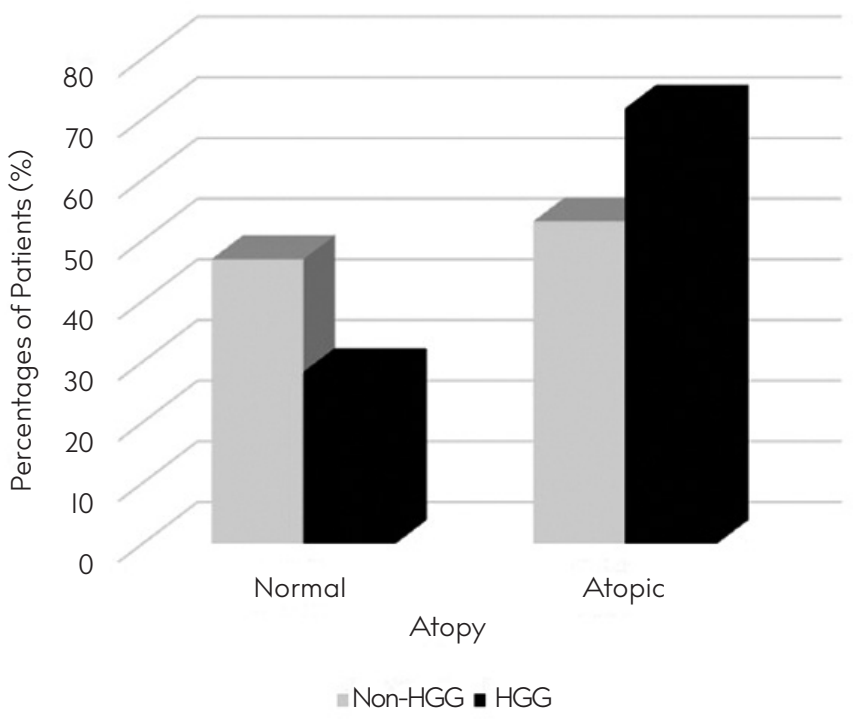

FIGURE 2. Presence of atopy in the non-HGG and HGG groups 


\section{DISCUSSION}

Among the 160 children evaluated for PADs who had presented with recurrent infections and/or recurrent wheezing/cough, 97 (60.6\%) were identified as having HGG.

THGI was the most frequently diagnosed group of HGG that affected approximately half of our study population. This result was in accordance with a study performed in Turkey (6) reporting THGl as the most frequently detected PAD with a prevalence rate of 7/100,000. On the other hand, studies from Europe, Australia, and Japan reported SIgAD as the most common type of PAD (3, 14-16). In addition, CVID was reported as the most frequently diagnosed PAD in Ireland, Norway, and Egypt (17-19).

Especially in CVID cases, high prevalence of consanguineous marriage and autosomal recessive trait were claimed to be the reason for the high prevalence (3). In a study reported from Turkey, the rate of consanguineous marriage among the parents of children with PAD was found to be $9.7 \%$ (8), which was higher than that in our study population (3\%).

In our study, males (61.9\%) were more affected with PADs than females (38.1\%), which was consistent with studies from Turkey, Europe, Iran, Kuwait, Israel, and Australia (8, 20-24).

IgG subgroup deficiency was the second most common type of PAD in our study population. The majority of cases belonged to the IgG3 deficiency group (96.77\%), and one patient belonged to the IgG2 deficiency group (3.2\%). In a previous study, the prevalence of IgG subgroup deficiency was reported to be $4.6 / 100,000$, making it the third most common type of antibody deficiency (8). Karaca et al. (25) reported that IgG3 deficiency was the most common IgG subgroup deficiency with a prevalence rate of $77 \%$, whereas isolated IgG2 deficiency was detected in $9 \%$ of the patients. In another study, lgG2 deficiency was reported as the leading IgG subgroup deficiency (25).

In our study, patients with THGl had the youngest age at the time of diagnosis (27 \pm 16.40 months), and those with CVID had the oldest age at the time of diagnosis ( $81.62 \pm 49.9$ months old) compared with children in other PAD groups. These results were consistent with those of previous studies, e.g., 16.8 months for THGI cases and60 months for CVID cases at the time of diagnosis (26) and 45.12 \pm 31.08 months for THGI cases and87.96 \pm 58.44 months for CVID cases (27). In general, the majority of patients with CVID are diagnosed in late adolescence (28), which may be one of the reasons for the lower prevalence in our study.

In our study, recurrent infection was the most common presenting clinical feature in children with PADs (86.6\%), which was consistent with the studies done in Turkey (58\%) (6), Iran (89.6\%) (3), Taiwan (54.5\%) (29), and USA (87\%) (30).

Among patients with PADs, 13 (I3.4\%) were admitted to the Division with only recurrent bronchoconstriction and wheezing. Among the PAD group of patients, six (4.6\%) had THGI, five (3.8\%) had IgG subgroup deficiency, I (7.7\%) had PHGl, and I (7.7\%) had IgM deficiency who presented with only asthmatic symptoms. In different studies, 5.4\% (3) and 36.4\% (26) of patients with PAD were reported to have asthmatic symptoms. In addition, $7 \%-8 \%$ of children with slgMD were reported to have allergic diseases and asthma (3I). In our study, despite the high atopy rates among patients with IgMD (50\%), 16.6\% of them had allergic asthma. Karaca et al. (25) reported 15\% of atopy in Turkish children with IgG subgroup deficiency, and Chong et al. (25) reported $40 \%$ of allergic cases. In our study, 23 of the 31 patients were evaluated for atopy, and $17(73.9 \%)$ were found to be atopic. Atopy was much more common in our patients with PAD compared to that in other studies.

In addition to infections, it has been reported that allergic symptoms occur as the first clinical manifestations of PADs (4.2\%) (3), as also found in our study. The tendency to develop allergy among patients with SIgAD (22.2\%) has been reported to be higher than that of other types of PADs $(32,33)$. However, in our study, children with IgGSD (73.9\%), followed by those with THGI (68\%), had higher rates of atopy. A dysregulation in the immune response contributing to defective antigen elimination in early childhood has been postulated to be a critical risk factor for the development of allergy (3I).

The treatment given to these patients depends on the severity and frequency of symptoms. Mild cases with PAD can be observed without any treatment. Ig replacement is one of the important treatments in PAD. Three (8.8\%) patients had received IVIG therapy.

Regarding the study limitations, larger number of patients could be included and the follow-up period could be extended to decide the number and type of certain PADs more clearly. Another limitation was that some of the patients had stopped coming for follow-up to our hospital according to their own will, so that we could not analyze any data obtained during the follow-up period, which reduced the amount of obtained information about the patients after the long-term follow-up.

In conclusion, early diagnosis and treatment of PAD are important for decreasing the morbidity and increasing the quality of life of those patients. Appropriate and early treatment would also decrease the healthcare costs. PADs have the highest prevalence among PIDs in several countries. In our study, the THGI and IgG subgroup deficiencies were the most common antibody deficiencies that may present not only with recurrent infections but also with recurrent bronchoconstriction unresponsive to standard asthma treatment. Evaluation of the immune system should be considered in children presenting with these types of clinical symptoms.

Creating a successful registry of PADs in North Cyprus would provide authorities adequate information for developing strategies for both diagnosis and treatment of patients with PADs.

Ethics Committee Approval: Ethics committee approval was received for this study from the Near East University Scientific Research Ethics Evaluation Board (Approval Date: 18.01.2017, Approval Number: YDU /2017/43359).

Informed Consent: Informed consent is not necessary due to the retrospective nature of this study.

Peer-review: Externally peer-reviewed. 
Author contributions: Concept - N.B., B.S.; Design - B.S., O.Y; Supervision - N.B.; Resource - B.S., O.Y.; Materials - N.B.; Data Collection and/or Processing - B.S., O.Y; Analysis and/or Interpretation - B.S., O.Y; Literature Search - B.S., O.Y.; Writing - B.S., O.Y.; Critical Reviews - N.B.

Conflict of Interest: The authors have no conflicts of interest to declare.

Financial Disclosure: The authors declared that this study has received no financial support.

\section{REFERENCES}

I. Adelman DC, Casale TB, Corren J. Manual of Allergy and Immunology, 5th ed. Philadelphia: Lippincott Williams d Wilkins; 2012. p.I5071.

2. Mohammadzadeh I, Moazzami B, Ghaffari J, Aghamohammadi A, Rezaei N. Primary immunodeficiency diseases in Northern Iran. Allergol Immunopathol (Madr) 2017;45(3): 244-250. [CrossRef]

3. Mohammadinejad P, Pourhamdi S, Abolhassani H, Mirminachi B, Havaei A, Masoom SN, et al. Primary Antibody Deficiency in a Tertiary Referral Hospital: A 30-Year Experiment. J Investig Allergol Clin Immunol 20I5; 25(6): 416-25.

4. Picard C, Al-Herz W, Bousfiha A, Casanova JL, Chatila T, Conley $\mathrm{ME}$, et al. Primary Immunodeficiency Diseases: an Update on the Classification from the International Union of Immunological Societies Expert Committee for Primary Immunodeficiency 2015. J Clin Immuno 2015; 35(8): 696-726. [CrossRef]

5. Ballow M. Primary immunodeficiency disorders: antibody deficiency. J Allergy Clin Immunol 2002; 109(4): 581-91. [CrossRef]

6. Kilic SS, Ozel M, Hafizoglu D, Karaca NE, Aksu G, Kutukculer N. The prevalences [correction] and patient characteristics of primary immunodeficiency diseases in Turkey--two centers study. J Clin Immunol 2013; 33(I): 74-83. [CrossRef]

7. Spickett G. Oxford Handbook of Clinical Immunology and Allergy. 3rd ed. Oxford: Oxford University Press; 20I3. p.I-33. [CrossRef]

8. Keles S, Artac H, Kara R, Gokturk B, Ozen A, Reisli I. Transient hypogammaglobulinemia and unclassified hypogammaglobulinemia: 'similarities and differences'. Pediatr Allergy Immunol 20I0; 2I(5): 843-5I. [CrossRef]

9. Paul ME, Shearer WT.The child who has recurrent infection. Immunol Allergy Clin North Am, 1999; 19(2); 423-33. [CrossRef]

10. Woroniecka M, Ballow M. Office evaluation of children with recurrent infection. Pediatr Clin North Am 2000; 47(6): 121I-24. [CrossRef]

II. Global Initiative for Asthma. Pocket Guide For Asthma Management and Prevention for Children 5 years and Younger (Internet). 2015 (cited 2015 December I). Available from: URL: http://www.ginasthma.org

12. Aksu G, Genel F, Koturoglu G, Kurugol Z, Kutukculer N. Serum immunoglobulin ( $\lg G, \lg M, \lg A$ ) and $\lg G$ subclass concentrations in healthy children: a study using nephelometric technique. Turk J Pediatr 2006; 48(I): 19-24.

13. Ikinciogullari A, Kendirli T, Dogu F, Egin Y, Reisli I, Cin S, et al. Peripheral blood lymphocyte subsets in healthy Turkish children. Turk $\mathrm{J}$ Pediatr 2004; 46(2): 125-30.

14. Salehzadeh M, Aghamohammadi A, Rezaei N. Evaluation of immunoglobulin levels and infection rate in patients with common variable immunodeficiency after immunoglobulin replacement therapy. J Microbiol Immunol Infect 20I0; 43(I): II-7. [CrossRef]

15. Vajic CM, Mao L, van Leeuwen MT, Kirkpatrick P, Grulich AE, Riminton S. Are antibody deficiency disorders associated with a narrower range of cancers than other forms of immunodeficiency? Blood 20I0; II6(8): 1228-34. [CrossRef]

16. Ishimura M, Takada H, Doi T, Imai K, Sasahara $Y$, Kanegane H, et al. Nationwide survey of patients with primary immunodeficiency diseases in Japan. J Clin Immunol 2011; 3I(6): 968-76. [CrossRef]

17. Stray-Pedersen A, Abrahamsen TG, Froland SS. Primary immunodeficiency diseases in Norway. J Clin Immunol 2000; 20(6): 477-85. [CrossRef]

18. Abuzakouk M, Feighery C. Primary immunodeficiency disorders in the Republic of Ireland: first report of the national registry in children and adults. J Clin Immunol 2005; 25(I): 73-7. [CrossRef]

19. Reda SM, Afifi HM, Amine MM. Primary immunodeficiency diseases in Egyptian children: a single-center study. J Clin Immunol 2009; 29(3): 343-51. [CrossRef]

20. Gathmann B, Grimbacher B, Beaute J, Dudoit Y, Mahlaoui N, Fischer $A$, et al. The European internet-based patient and research database for primary immunodeficiencies: results 2006-2008. Clin Exp Immunol 2009;157 Suppl I :3-II. [CrossRef]

21. Baumgart KW, Britton WJ, Kemp A, French M, Roberton D. The spectrum of primary immunodeficiency disorders in Australia. J Allergy Clin Immunol 1997; 100(3): 415-23. [CrossRef]

22. Golan H, Dalal I, Garty BZ, Schlesinger M, Levy J, Handzel Z, et al. The incidence of primary immunodeficiency syndromes in Israel. Isr Med Assoc J 2002; 4(II Suppl): 868-7l.

23. Rezaei N, Mohammadinejad P, Aghamohammadi A. The demographics of primary immunodeficiency diseases across the unique ethnic groups in Iran, and approaches to diagnosis and treatment. Ann N Y Acad Sci 20II; 1238: 24-32. [CrossRef]

24. Al-Herz W. Primary immunodeficiency disorders in Kuwait: First report from Kuwait national primary immunodeficiency registry. $J$ Clin Immuno. 2008; 28: 186-93. [CrossRef]

25. Karaca NE, Karadeniz C, Aksu G, Kutukculer N. Clinical and laboratory evaluation of periodically monitored Turkish children with IgG subclass deficiencies. Asian Pac J Allergy Immunol 2009; 27(I): 438.

26. Wang LJ, Yang YH, Lin YT, Chiang BL. Immunological and clinical features of pediatric patients with primary hypogammaglobulinemia in Taiwan. Asian Pac J Allergy Immunol 2004; 22(I): 25-3I.

27. Ozen A, Baris S, Karakoc-Aydiner E, Ozdemir C, Bahceciler NN, BarIan IB. Outcome of hypogammaglobulinemia in children: immunoglobulin levels as predictors. J Reprod Immunol 20I0; 137(3): 374-83. [CrossRef]

28. Hermaszewski R.A and Webster A.D.B. Primary hypogammaglobulinemia: a survey of clinical manifestations and complications. Q J Med 1993; 86: 31-42

29. de Silva NR, Gunawardena S, Rathnayake D, Wickramasingha GD Spectrum of primary immunodeficiency disorders in Sri Lanka. Allergy Asthma Clin Immunol 2013; 9(I): 50. [CrossRef]

30. Onigbanjo MT, Orange JS, Perez EE, Sullivan KE. Hypogammaglobulinemia in a pediatric tertiary care setting. Clin Immunol 2007; 125(I): 52-9. [CrossRef]

31. Szczawinska-Poplonyk A. An overlapping syndrome of allergy and immune deficiency in children. J Allergy 2012; 2012: 658279. [CrossRef]

32. Aghamohammadi $A$, Cheraghi $T$, Gharagozlou $M$, Movahedi $M$, Rezaei $N$, Yeganeh $M$, et al. IgA deficiency: correlation between clinical and immunological phenotypes. J Clin Immunol 2009; 29(I): 130-6. [CrossRef]

33. Janzi M, Kull I, Sjoberg R, Wan J, Melen E, Bayat N, et al. Selective IgA deficiency in early life: association to infections and allergic diseases during childhood. Clin Immunol 2009; 133(I): 78-85. [CrossRef] 